\title{
Implementasi Pembangunan Jaringan Mini Optical Line Termination di Kawasan Babelan milik PT Telekomunikasi Indonesia
}

\author{
Mathias Radi Satriadi ${ }^{1}$, Rully Pramudita ${ }^{2}$ \\ ${ }^{1}$ Teknik Informatika, Universitas Bina Insani; Jl. Siliwangi No. 6 Rawa Panjang, Kota Bekasi, \\ Jawa Barat e-mail: radimathiass@gmail.com, \\ ${ }^{2}$ Manajemen Informatika, Universitas Bina Insani; JI. Siliwangi No. 6 Rawa Panjang, Kota \\ Bekasi, Jawa Barat e-mail:rullypramudita@binainsani.ac.id
}

Diterima: 26 Juni 2021; Review: 27 Juni 2021; Disetujui: 30 Juni 2021

Cara sitasi: Satriadi M R, Pramudita R. 2021. Implementasi Pembangunan Jaringan Mini Optical Line Termination di Kawasan Babelan milik PT Telekomunikasi Indonesia. Information Management For Educators And Professionals Vol 5 (2): 63-74.

\begin{abstract}
Abstrak: Penelitian dengan judul pembangunan mini optical line termination di Kawasan Babelan, tujuan penelitian ini untuk mempelajari infrastruktur terbaru milik PT Telekomunikasi Indonesia yang mengembangkan jaringanya terus menerus untuk menjangkau wilayah yang belum mendapatkan akses internet, proses pembangunan jaringan fiber optik, PT Telekomunikasi Indonesia (Telkom) sebagai Badan Usaha Milik Negara (BUMN) yang berkonsenterasi pada bidang komunikasi, berhasil meluncurkan produk Internet Home (INDIHOME) sebagai Brand Image-nya guna memenuhi kebutuhan informasi komunikasi demi kemajuan bangsa Indonesia. Metode pengumpulan data meliputi studi lapangan dan studi pustaka. Studi lapangan meliputi praktek, wawancara dan pengamatan. Studi pustaka dilakukan dengan penilitian kepustakaan yang relevan dengan masalah yang dihadapi. Dari analisa dan pengamatan yang dilakukan bahwa jaringan akses fiber optik merupakan salah satu peningkatan yang baik guna meningkatkan efisiensi yang berpengaruh pada kecepatan mengirimkan paket data (internet).
\end{abstract}

Kata kunci: Fiber Optik, Jaringan, Indihome, Optical Line Termination (OLT)

Abstract: The research entitled the construction of a mini optical line termination in the Babelan area, the purpose of this research is to study the latest infrastructure owned by PT Telekomunikasi Indonesia which is developing its network continuously to reach areas that do not yet have internet access, the process of building a fiber optic network, PT Telekomunikasi Indonesia (Telkom) as The State-Owned Enterprises (BUMN), which concentrate on the communication sector, have successfully launched the Internet Home (INDIHOME) product as its Brand Image to meet the needs of communication information for the progress of the Indonesian nation. Data collection methods include field studies and literature studies. Field studies include practice, interviews and observations. Literature study is carried out with literature research that is relevant to the problem at hand. From the analysis and observations made that the fiber optic access network is one of the best improvements to improve efficiency which affects the speed of sending data packets (internet).

Keywords: Fiber Optic, Network, Indihome, Optical Line Termination (OLT)

\section{Pendahuluan}

Perkembangan teknologi telekomunikasi yang kini sangat pesat, manusia di seluruh dunia tak pernah puas dengan informasi serta komunikasi, terutama di Indonesia. GPON adalah teknologi yang mampu memberikan layanan dengan kecepatan hingga 2.4 Gbps untuk upstream dan downstream. Perancangan ini diharapkan dapat menjadi referensi penelitian dan menjadi solusi untuk mempercepat pembangunan jaringan fiber optik dengan mengunakan Teknologi yang sedang berkembang sekarang. Perkembangan layanan komunikasi yang 
tersedia di Indonesia saat ini ada dua jenis, yaitu yang menggunakan kabel seperti telepon rumah maupun menggunakan sinyal digital seperti handphone. mengganti pemakaian kabel tembaga dengan kabel Fiber Optik yang memiliki kecepatan pengantaran data jauh lebih cepat dari pada kabel tembaga. Perusahaan yang mengikuti perkembangan ini yaitu PT Telekomunikasi Indonesia, Tbk atau lebih dikenal dengan nama PT.Telkom. PT.Telkom merupakan perusahaan yang besar di mana satu-satunya perusahaan di bidang teknologi, informasi dan komunikasi yang dimiliki Badan Usaha Milik Negara (BUMN). PT.Telkom adalah perusahaan pertama di Indonesia yang berfokus pada perkembangan dunia teknologi, informasi dan komunikasi di Indonesia dari masa kolonial Belanda hingga saat ini. PT.Telkom ini yaitu IndiHome Fiber optik atau lebih dikenal dengan IndiHome (INDIHOME) sebagai Brand Image-nya. PT.Telekomunikasi Indonesia (PT.Telkom) sebagai Badan Usaha Milik Negara (BUMN) yang berkonsentrasi pada bidang komunikasi, guna memenuhi kebutuhan informasi komunikasi demi kemajuan bangsa Indonesia. Dengan dilakukannya pembangunan insfrastruktur tersebut diharapkan akan meningkatkan pemanfaatan teknologi informasi yang lebih maksimal lagi di wilayah Jawa Barat, khususnya kota Bekasi. Namun di samping pembangunan insfrastruktur, menjaga jaringan yang sudah terbangun merupakan salah satu hal yang sangat penting guna menjaga kepuasan pelanggan yang sudah menggunakan layanan Indihome. Dengan adanya "Implementasi Pembangunan Mini Optical Line Termination di Kawasan Babelan" diharapkan dapat diimplementasikan untuk promosi dan peluasan jaringan telekomunikasi pada daerah yang belum mendapatkan jaringan fiber optik.

Sensor fiber optik dapat diterapkan sebagai sensor yang tertanam didalam beton dengan konfigurasi tertentu guna mengukur sifat-sifat fisik dari beton secara berkesinambungan seperti parameter regangan dan pergeseran elemen struktur beton.[2]

\section{Metode Penelitian}

Metodologi penelitian adalah suatu cara yang digunakan dalam pengumpulan, pengolahan dan penganalisaan data dengan cara-cara ilmiah. Adapun pengumpulan data yang penulis gunakan adalah sebagai berikut:

\section{Observasi}

Observasi adalah pengamatan dan pencatatan secara sistematis terhadap unsur-unsur yang tampak dalam suatu gejala dalam objek penelitian. Penelitian observasi dibutuhkan untuk dapat memahami proses terjadinya wawancara dan hasil wawancara dapat dipahami dalam konteksnya. [8]. Observasi yang dilakukan dalam penelitian ini dengan cara mengamati secara langsung kegiatan pembangunan yang dilakukan oleh PT Telekomunikasi Indonesia pada hari selasa, 19 januari 2021 yang beralamat di jalan Rawa Tembaga IV No.4 Marga Jaya, Bekasi Selatan, Kota bekasi. Hasil observasi yang didapatkan berupa data primer yang di butuhkan untuk penulisan.

\section{Wawancara}

Wawancara adalah komunikasi antara dua buah pihak atau lebih yang bisa dilakukan dengan tatap muka dimana salah satu pihak berperan sebagai pewawancara dan pihak lainnya sebagai narasumber dengan tujuan tertentu, misalnya untuk mendapatkan informasi atau mengumpulkan data. [6]. Kegiatan wawancara dilakukan untuk memperoleh data primer yang belum diperoleh pada saat observasi. Dalam penelitian ini wawancara dilakukan dengan Andi Armal selaku tim yang melakukan proses configing atau menanamkan data pada perangkat Mini OLT. Wawancara dilakukan pada hari Sabtu, 23 januari 2021 dan hasil wawancara tidak hanya berupa data primer, tetapi dapat juga berupa bentuk data sekunder yang mungkin saja diberikan oleh narasumber dalam bentuk data yang telah selesai diolah oleh narasumber dan sumber data.

\section{Studi Pustaka}

Studi pustaka adalah pencarian sumber-sumber atau opini pakar tentang suatu hal yang berkaitan dengan tujian penelitian. Dengan kata lain, studi pustakan merupakan pengkajian beberapa sumber pustaka yang terkait dengan variable-variabel utama atau topik sebuah penelitian. Maka dapat dikatakan bahwa hampi setiap jenis penelitian memasukan studi pustaka sebagai salah satu langkah yang ditempuh dalam keseluruhan penelitian. [4]. Studi pustaka dilakukan dalam keseluruhan proses penelitian sejak awal hingga sampai akhir penelitian, dengan melakukan aktivitas pencarian data dan 36 informasi berupa teori melalui buku-buku, jurnal, sumber bacaan elektronik, memanfaatkan berbagai macam pustaka yang relevan dengan penelitian yang tengah dicermati untuk memperoleh data penunjang. Dalam ini 
penulis menganalisa sistem dengan menggunakan model pengembangan PPDIOO. Dimana metode ini memiliki beberapa urutan dalam pengerjaanya. Urutan dan penjelasan model PPDIOO dapat dilihat pada gambar dibawah ini:

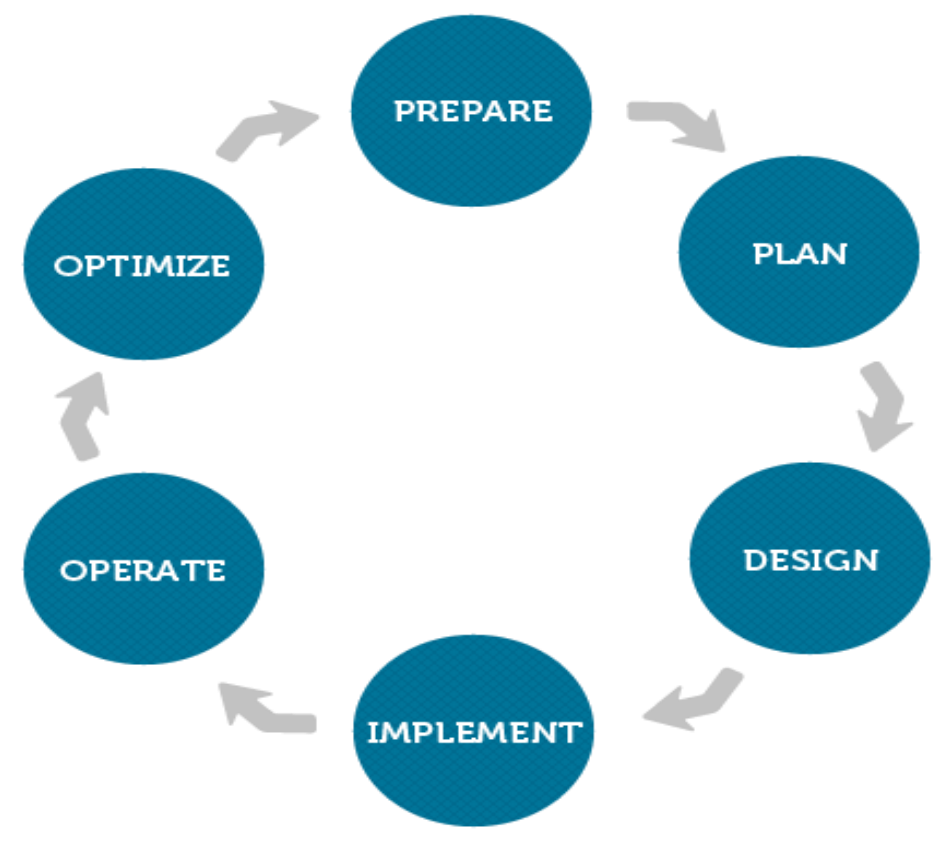

Sumber:[9]

Gambar 1. Urutan Metode PPDIOO

\section{Prepare}

Melibatkan penerapan persyaratan organisasi (bisnis), mengembangkan strategi jaringan, mengusulkan arsitektur konseptual tingkat tinggi dan mengindentifikasi teknologi terbaik yang dapat mendukung arsitektur jaringan[9].

Plan

Melibatkan identifikasi kebutuhan jaringan awal berdasarkan tujuan, fasilitas, kebutuhan pengguna, kebutuhan hardware/software dan sebagainya. Tahap rencana melibatkan karakteristik situs dan menilai jaringan yang ada dan melakukan analisis untuk menentukan apakah infrastruktur yang ada sistem dan lingkungan operasional dapat mendukung sistem yang diusulkan[10].

Design

Persyaratan awal yang tentukan dalam tahapan perencanaan mendorong kegiatan spesialis desain jaringan. Spesifikasi desain jaringan yang dihasilkan adalah desain rinci komprehensif yang memenuhi kebutuhan bisnis saat ini dan kebutuhan teknis lalu menggabungkan spesifikasi untuk mendukung ketersediaan, keandalan, keamanan, skalabilitas dan kinerja. Spesifikasi desain adalah dasar untuk melaksanakan kegiatan [9].

Implement

Jaringan yang dibangun atau komponen tambahan lainnya dimasukkan sesuai dengan spesifikasi desain dengan tujuan mengintegrasikan perangkat tanpa menggangu jaringan yang ada atau membuat titik kerentanan. Implementasi dan verifikasi dimulai setelah disain telah disetujui [9].

Operate

Operasi adalah tujuan akhir dari kesesuaian desain yang sudah rancang. Tahapan operasional melibatkan pemeliharaan/menjaga jaringan komputer melalui kegiatan pada setiap harinya, termasuk menjaga ketersediaan jaringan yang tinggi dan mengurangi biaya. Pendeketsian kesalahan, koreksi dan pemantauan kinerja yang terjadi dalam kegiatan seharihari memberikan data awal untuk tahapan optimasi siklus jaringan komputer [9].

Optimize

Melibatkan manajemen jaringan yang proaktif. Tujuan dari manajemen proaktif adalah untuk mengidentifikasi dan menyelesaikan masalah sebelum masalah nyata muncul dan dapat 
mempengaruhi organisasi. Deteksi dan koreksi kesalahan relatif (troubleshooting) dibutuhkan ketika manajemen proaktif tidak dapat memprediksi dan mengurangi kegagalan [9].

Kerangka pemikiran yang dibuat dalam penelitian ini dimulai dari identifikasi masalah hinga analisis. Berikut adalah hasil dari penelitian yang dilakukan yaitu:

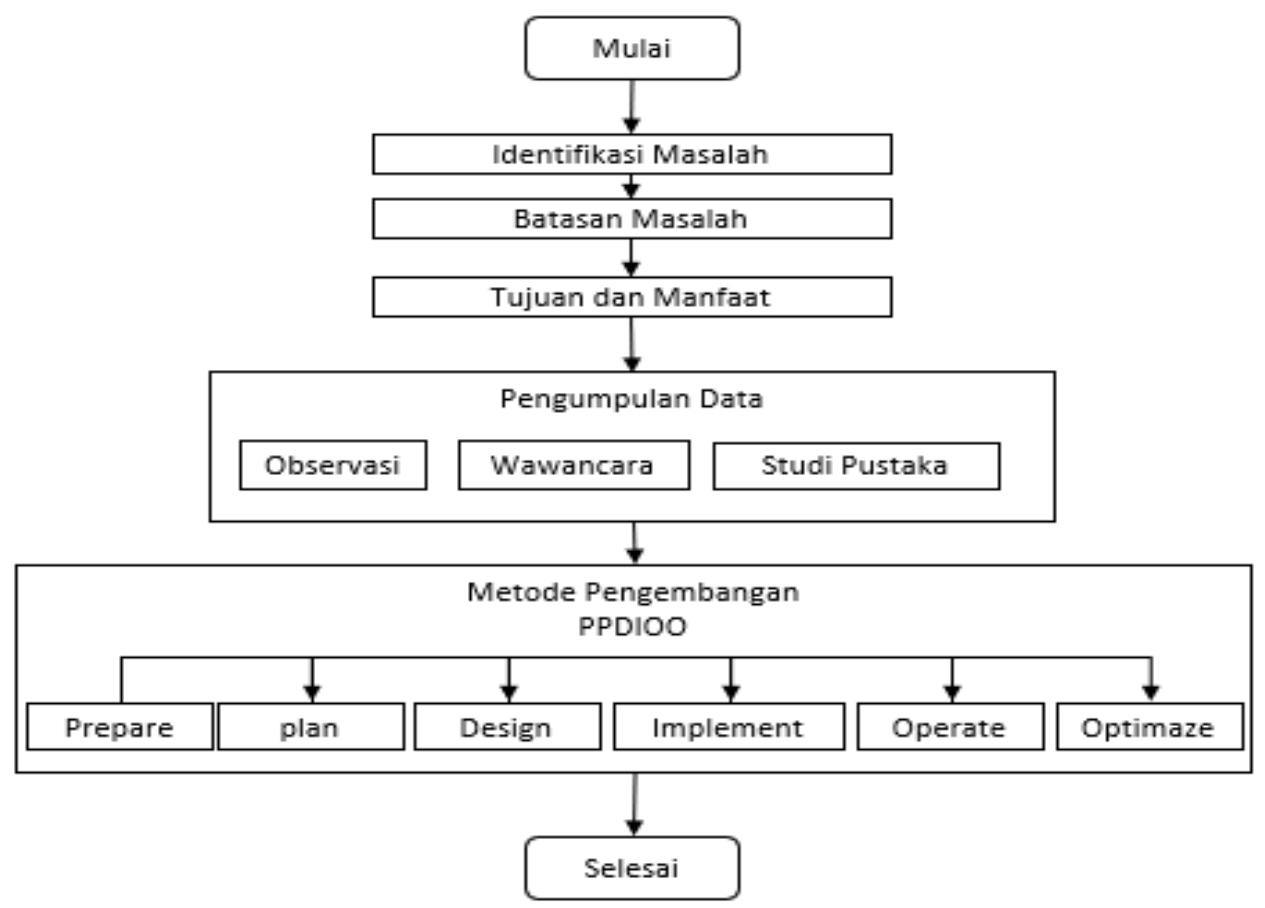

Sumber : Hasil Penelitian 2020

Gambar 2. Kerangka Pemikiran

Bedasarkan kerangka pemikiran yang telah digambarkan di atas, maka dapat diuraikan pembahasan masing- masing tahap dalam penelitian adalah sebagai berikut :

Identifikasi Masalah Pada tahap ini dilakukan identifikasi masalah pada pembangunan mini olt yang sedang dilakukan. Dengan demikian, penulis dapat menemukan kendala-kendala dan permasalahan yang terjadi, sehingga penulis dapat mencari solusi dari permasalahan tersebut.

Batasan Masalah Pada tahap ini penulis akan membatasi jangkauan proses yang akan dibahas pada Implementasi Pembangunan Mini OLT. Dengan demikian, penulis dapat memfokuskan pada satu persoalan yang akan dilakukan.

Tujuan dan manfaat dari implementasi ini diharapkan dapat memberikan pengetahuan mengenai teknologi terbaru yang akan dipakai oleh PT Telekomunikasi Indonesia dan proses pembangunannya.

Pengumpulan Data Dengan melakukan penelitian dan pengamatan secara langsung terhadap obyek penelitian untuk menemukan masalah-masalah mengenai Implementasi Pembangunan Mini OLT, maka peneliti melakukan observasi untuk memudahkan pengerjaan penelitian dan melakukan wawancara untuk mendapatkan informasi yang valid, serta melakukan studi pustaka untuk mengumpulkan data yang dilakukan secara keseluruhan dari awal hingga akhir penelitian dengan melakukan aktivitas pencarian data dan informasi berupa teori melalui buku-buku, jurnal, sumber bacaan elektronik, memanfaatkan berbagai macam pustaka yang relevan dengan penelitian yang tengah dicermati untuk memperoleh data penunjang.

\section{Hasil dan Pembahasan}

Perangkat Keras(Hardware)

Perangkat keras yang digunakan dalam pembangunan jaringan Mini OLT ini dapat dilihat dari gambar 3. 


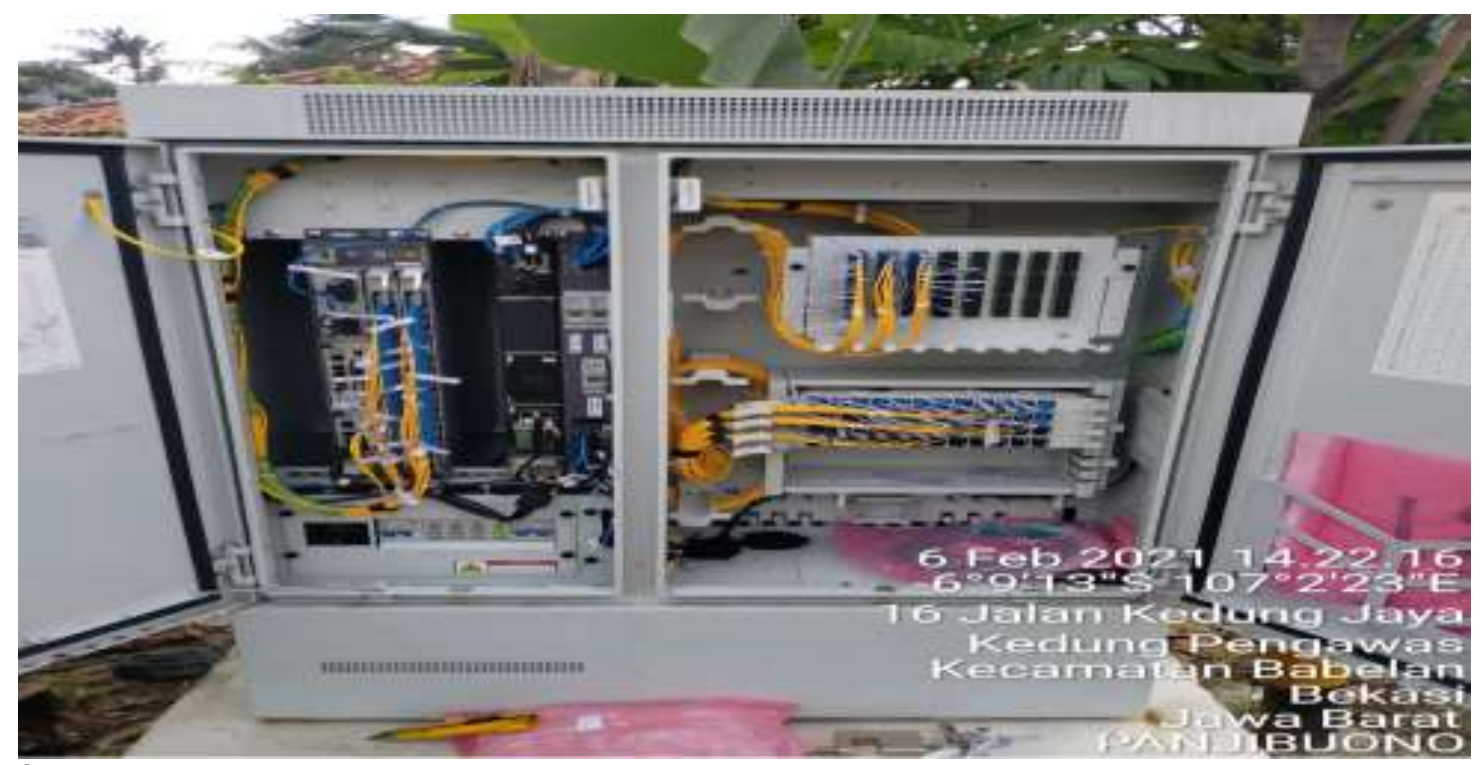

Sumber : Hasil Penelitian 2020

Gambar 3. Gambar Mini OLT

Adapun penjelasan mengenai fungsi dari perangkat keras yang digunakan dalam mini OLT adalah sebagai berikut:

Table 1. Keterangan Fungsi Perangkat Keras

\begin{tabular}{|c|c|}
\hline Gambar & Keterangan \\
\hline & $\begin{array}{l}\text { Patch Cord merupakan kabel fiber optik yang digunakan untuk } \\
\text { mentransmisikan sinyal yang berbentuk cahaya }\end{array}$ \\
\hline 11 & $\begin{array}{l}\text { Cabinet Mini OLT dengan seri F01S200 merupakan cabinet yang } \\
\text { digunakan untuk melindungi modul Gpon dan untuk terminasi } \\
\text { patch cord. }\end{array}$ \\
\hline 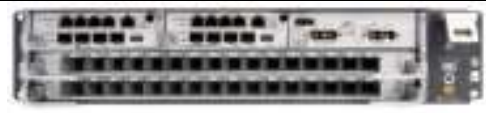 & $\begin{array}{l}\text { Shelf(rak) Huawei smartAX MA5800-X2 adalah perangkat yang } \\
\text { digunakan dalam pembangunan Mini OLT dikawasan Babelan. }\end{array}$ \\
\hline & $\begin{array}{l}\text { Modul Huawei FLHF merupakan modul yang dapat menampung } \\
16 \text { port gpon dengan satu port gpon berkapasitas } 32 \text { user. }\end{array}$ \\
\hline
\end{tabular}

Optical Power Meter merupakan alat untuk mengukur besaran gelombang pada fiber optik.

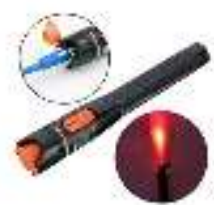

Visual Fault Locator adalah alat yang digunakan untuk mengetahui pembiasan cahaya yang lewat dari kabel fiber optik.

Sumber : Hasil Penelitian 2020

\section{Perancangan Perangkat Lunak (Software)}

Dalam pembangunan Mini Optical Line Termination ini mengunakan beberapa perangkat lunak diantaranya: ZOC7 Terminal merupakan aplikasi untuk melakukan Telnet atau memasuki sistem yang ada pada modul yang akan dipakai, dapat dijalankan mengunakan operating sistem windows maupun Mac Os. 


\section{Skema Jaringan Berjalan}

Skema jaringan berjalan akan membahas singkat mengenai tolopogi jaringan yang sudah ada sekarang. Layanan Triple play adalah istilah untuk pemasaran, yang artinya ada tiga layanan. Layanan ini meliputi internet dengan kecepatan tinggi, televisi dan layanan telepon [1].

\section{MSAN}

Perpaduan fleksibel dari layanan broadband dan narrowband dapat di integrasikan dari sebuah single platform seperti :Layanan, Transmisi, Topologi

MSAN memungkinkan beragam aplikasi seperti: FTTO (Fiber to The Office), FTTC (Fiber to The Curb), FTTB (Fiber to The Bulding) juga tersedia perangkat transmisi optik SDH atau PDH.

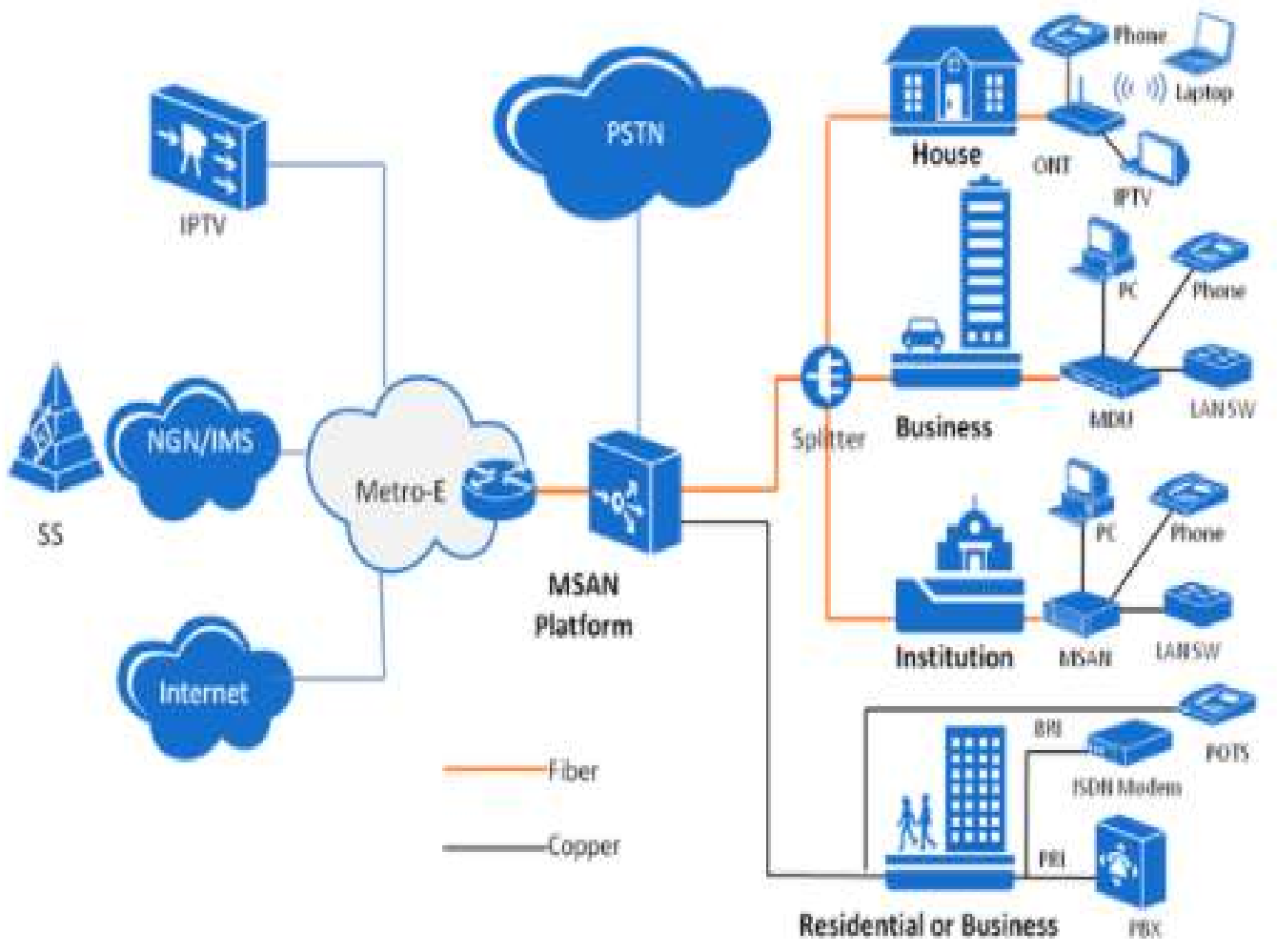

Sumber : [5]

Gambar 4. Topologi MSAN

MSAN memberikan keuntungan seperti dijelaskan pada tabel 2 berikut ini:

Tabel 2. Keuntungan MSAN

No. Keterangan

1. MSAN menyediakan layanan narrowband untuk data dan suara (menggunakan POTS, ISDN $P R A / B R A$, digital leased line) dan layanan broadband untuk kemampuan internet, data dan multimedia yang meningkatkan kemampuan download file dan penjelajahan internet yang lebih cepat bagi end-users.Dengan fleksibilitas kemampuan multiservice ini akan mampu menyediakan operator telekomunikasi suatu kapasitas penghasilan yang lebih besar.

2. Kabinet outdoor yang dikirimkan dalam bentuk complete-built yang telah mangalami proses pengujian di pabrik. Hal ini berarti node telah langsung siap untuk dioperasikan begitu dihubungkan dengan catuan listrik serta tersambung kejaringan transport dan koneksi ke end-user telah dibuat. Dari terminal local, provisioning system dapat dilakukan sehingga memungkinkan MSAN untuk dapat langsung operasional dalam waktu yang cukup pendek secara signifikan berarti mengefektifkan waktu yang diperlukan untuk mengatur pendapatan

3. MSAN dirancang untuk solusi multi vendor. Penggunaan interface standar diintegrasikan di layer transport, layer signaling dan level manajemen jaringan. Hal ini memungkinkan MSAN untuk secara penuh interoperable dengan peralatan vendor lain, sehingga dengan begitu memungkinkan operator untukmemilih solusi jaringan sesuai dengan pemeliharaan yang baik secara layer demi layer.

Sumber : Hasil Penelitian 2020 


\section{GPON}

Optical Line Terminal (OLT) atau biasa disebut juga dengan Optical Line Termination adalah perangkat yang berfungsi sebagai titik akhir (end-point) dari layanan jaringan optik pasif. Perangkat ini mempunyai dua fungsi utama, antara lain: a). Melakukan konversi antara sinyal listrik yang digunakan oleh penyedia layanan dan sinyal optik yang digunakan oleh jaringan optik pasif, b). Mengkoordinasikan multiplexing pada perangkat lain di ujung jaringan, atau biasa disebut dengan Optical Network Terminal (ONT) atau Optical Network Unit (ONU).

Panjang gelombang untuk upstream adalah $1310 \mathrm{~nm}$ dan panjang gelombang untuk downstream $1490 \mathrm{~nm}$ dan layanan yang diberikan adalah data, voice dan video dengan kecepatan mencapai hingga 2,4Gbps[3].

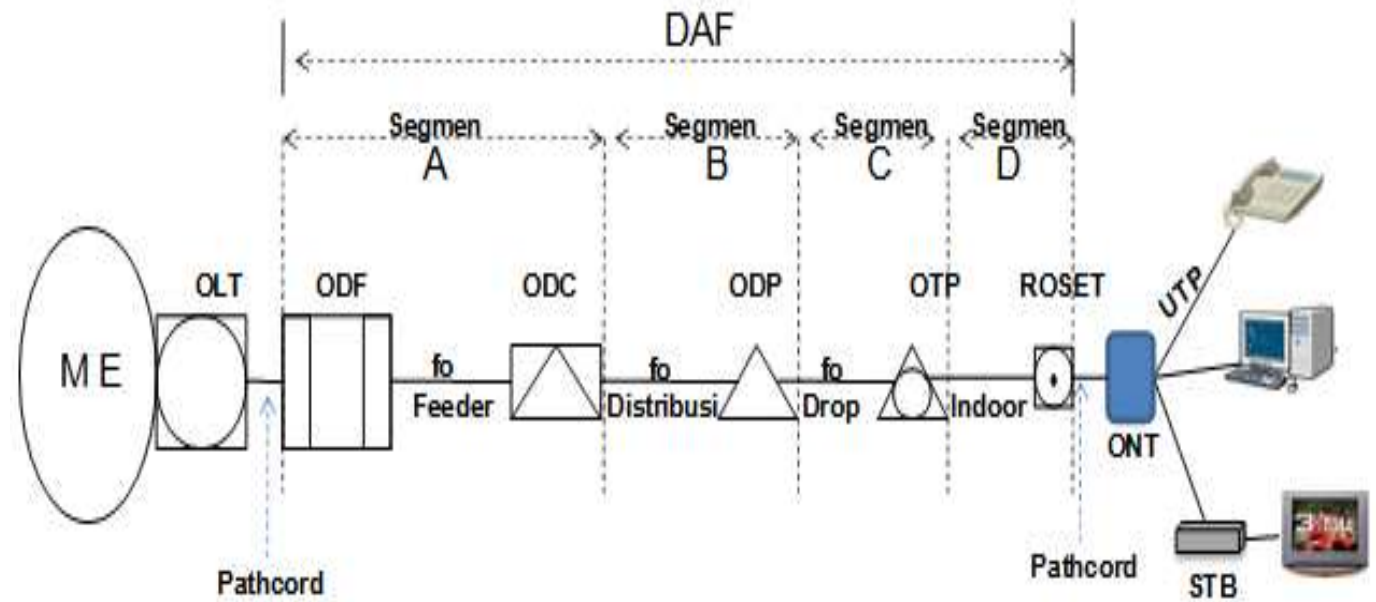

Sumber : [5]

Gambar 5. Topologi GPON

Rugi-rugi transmisi adalah suatu karakteristik bahan serat optik. Rugi-rugi ini menghasilkan penurunan dari daya cahaya dan juga penurunan bandwith dari sistem, kualitas transmisi informasi yang dibawa, efiensi dan kapasitas sistem yang secara keseluruahan [7].

\section{Prepare}

Dalam proses ini tim akan melakukan pendataan dan pengecekan material yang dibutuhkan untuk melasanakan pembangunan Mini OLT.

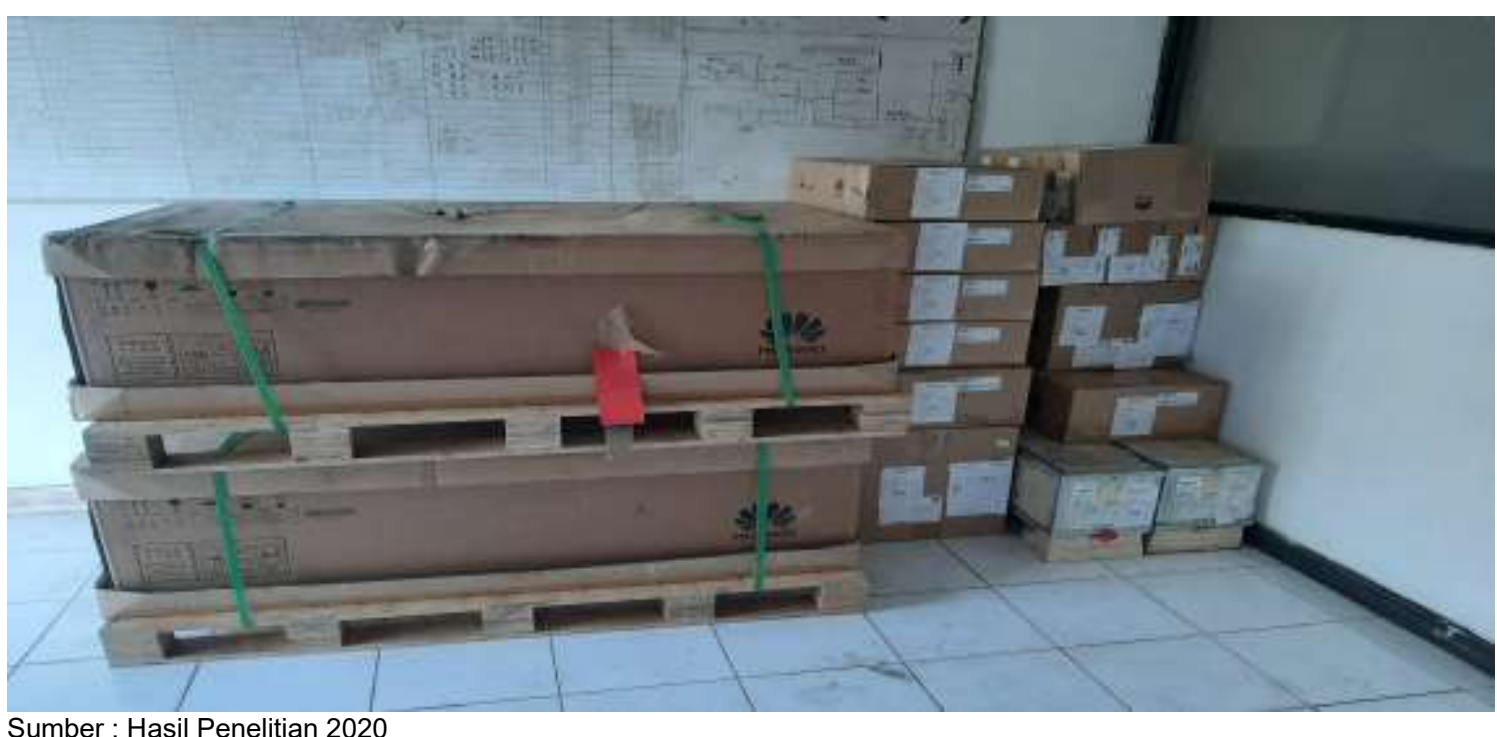

Sumber : Hasil Penelitian 2020

Gambar 6. Persiapan Barang 
Berikut ini adalah daftar barang yang diperlukan dalam membangun mini OLT dijelaskan pada tabel 3 berikut:

\begin{tabular}{clc} 
& & Tabel 3. List Barang \\
\hline No & Nama Barang & Jumlah \\
\hline $\mathbf{1}$ & Patch Cord SC-LC 3m & 4 Pcs \\
\hline $\mathbf{2}$ & Patch Cord SC-SC 3m & 64 Pcs \\
\hline $\mathbf{3}$ & Kabinet Mini OLT F01S200 & 1 Pcs \\
\hline $\mathbf{4}$ & Shelf Hwawei SmartAX MA5800-X2 & 1 Pcs \\
\hline $\mathbf{6}$ & Modul FLHF & 2 Pcs \\
\hline $\mathbf{7}$ & Optical Power Meter & 1 Pcs \\
\hline
\end{tabular}

Sumber : Hasil Penelitian 2020

Plan

Identifikasi syarat awal untuk melakukan pembangunan jaringan Mini OLT dengan mengecek persyaratan yang dibutuhkan untuk membangun Mini OLT: 1). Pembangunan Mini OLT harus dekat dengan ODC (Optical Distribution Cabinet) agar memudahkan penarikan feeder untuk akses layanan ke server, 2). Dan akan dilakukan pengecekan jaringan feeder dari kantor telkom babelan untuk memastikan ada Feeder yang masih tersedia minimal 4 core dan max 6 core untuk dilakukan penyambungan jalur transmisi sinyal untuk menghidupkan Mini OLT, 3). Pengecekan jaringan sambungan yang telah di cek tidak boleh melebihi rugi bending dan sambungan -1dbm agar terjamin kwalitas layanan yang akan dibangun, 4). Pondasi akan dibangun lebih awal agar memastikan bentuk dan kepadatan struktur tanah yang kuat untuk meletakan cabinet, 5). Setela pendirian cabinet Mini OLT akan dilakukan terminasi Patch Cord agar sesuai dengan standar kelayakan yang telah ditetapkan oleh PT Telekomunikasi Indonesia, 6). Pengaktifan pemeriksa suhu pada Mini OLT agar dapat memantau perangkat yang sudah dibangun, 7). Pemasangan battre di lakukan akhir setelah semua prosedur diatas dilakukan dengan tujuan mengantisipasi sort atau naik turunya tegangan secara langsung dari PLN dan meminimalisir kerusakan yang terjadi karena pemadaman listrik, 8). Setelah battre di pasang dan perangkat aktif akan dilakukan Pembuatan monitoring system Mini OLT dengan memasukan IP perangkat kedalam Monitoring Cacti.

\section{Design}

Topologi jaringan yang akan dibangun jaringanakan ditarik dari kantor untuk menghidupkan OLT diluar kantor diharapkan untuk mengecilkan biaya pembangunan.

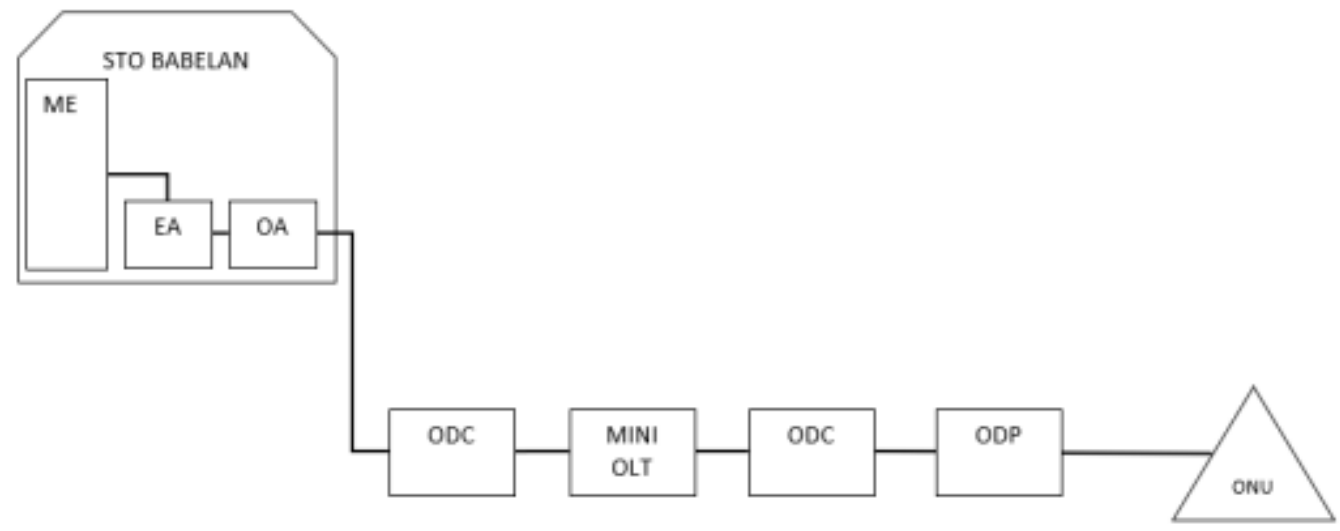

Sumber : Hasil Penelitian 2020

Gambar 7. Topologi Jaringan Mini OLT Babelan

Secara umum arsitektur jaringan dari Mini OLT Babelan adalah seperti berikut : 1). ME atau Metro Ethernet sering dianggap sebagai solusi komunikasi untuk menghubungkan dua titik (atau lebih) yang terpisah satu sama lain. Merupakan server yang mengatur jalanya seluruh layanan yang akan diberikan ke OLT, 2). FTM adalah perangkat yang berfungsi untuk mengelola terminasi dan koneksi kabel fiber optik antar perangkat aktif baik perangkat transmisi maupun akses, sebagai titik terminasi dari kabel fiber optik OSP dan sebagai titik koneksi antara perangkat aktif. EA adalah frame yang dibuat khusus untuk terminasi kabel fiber optik yang ada dalam ftm yang ditujukan hanya untuk sambungan ke metro e. Sedengkan OA atau 
out akses adalah frame yang di khususkan untuk penyambungan fider arah ke ODC, 3). ODC (Optical Distribuion Cabinet) atau perangkat Lemari Kabel Fiber Optik, yang bertujuan sebagai tempat penyambungan dan titik temu antara kabel fider dan kabel distribusi fiber optik, 4). OLT (Optical Line Terminal), atau perangkat yang mempunyai fungsi Titik Hubung dengan provider layanan Telepon, Internet/Data dan TV/ IP TV Pusat penyambungan dan distribusi layanan yang dikirim ke pelanggan. Pengaturan dan monitoring jaringan pelanggan. Mengkonversi sinyal layanan ke dalam bentuk sinyal optik, 4). ODP (Optical Distribution Point) atau kotak distrbusi layanan ke ont (modem Indihome), 5). ONT/ ONU (Optical Network Terminal atau Optical Network Unit.)Adalah modem yang disediakan PT Telekomunikasi Indonesia yang berfungsi untuk meng konfrensikan sinyal optik menjadi sinyal elektrik output yang diberikan oleh ONT berupa IP VOICE, IP TV dan internet.

\section{Implement}

Proses Pembuatan Pondasi untuk Mini OLT untuk memudahkan terminasi kabel feeder dan distribusi dijelaskan pada tabel 4 berikut ini:

Tabel 5. Pembuatan Pondasi Mini OLT

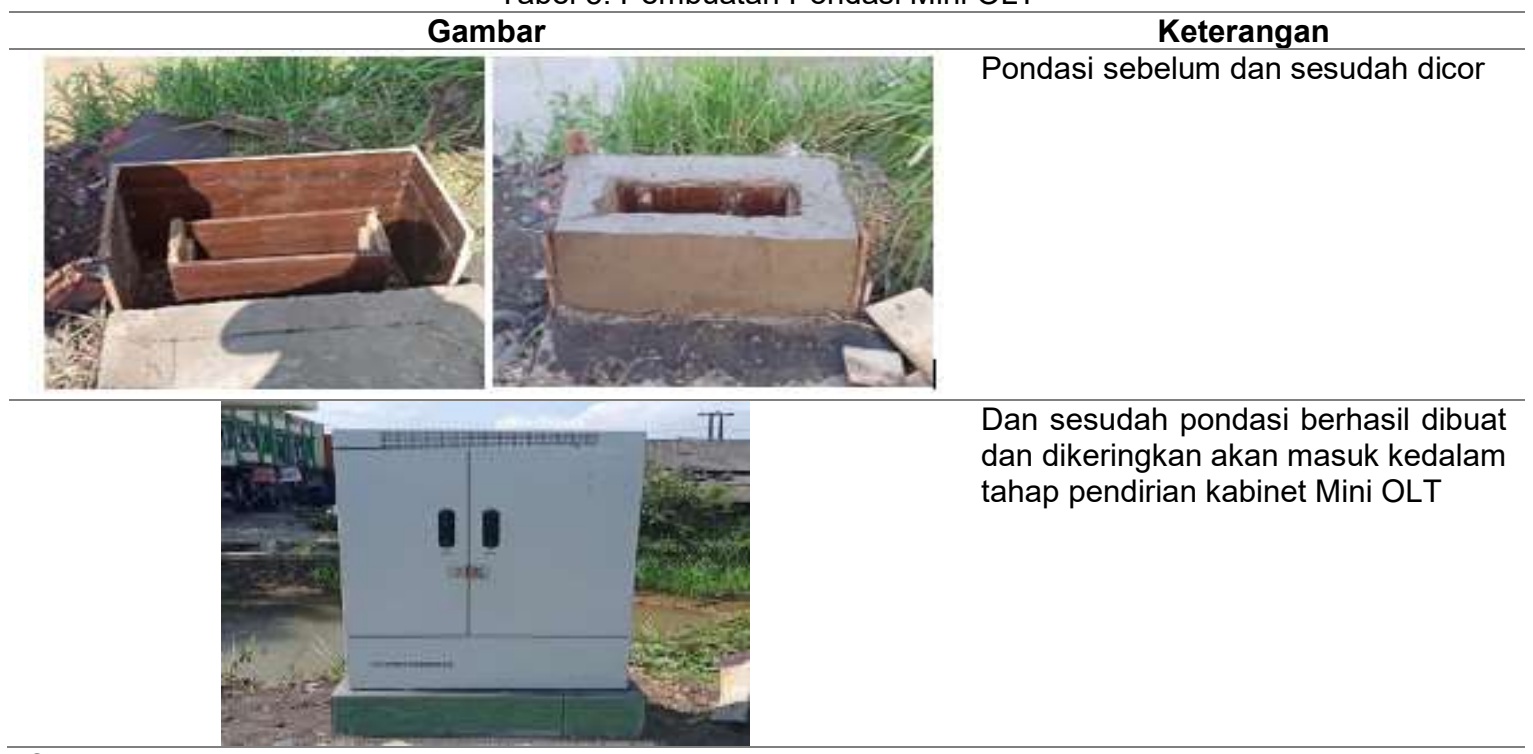

Sumber : Hasil Penelitian 2020

\section{Operate}

Pada langkah ini saya akan menjelaskan tahap- tahap pemberian layanan Internet, IP TV dan IP Voice pada Mini OLT dengan IP yang sudah ditentukan oleh PT Telekomunikasi Indonesia.

\begin{tabular}{|c|c|}
\hline \multicolumn{2}{|c|}{ Tabel 6. Tahap Pemberian Layanan } \\
\hline Gambar & Keterangan \\
\hline 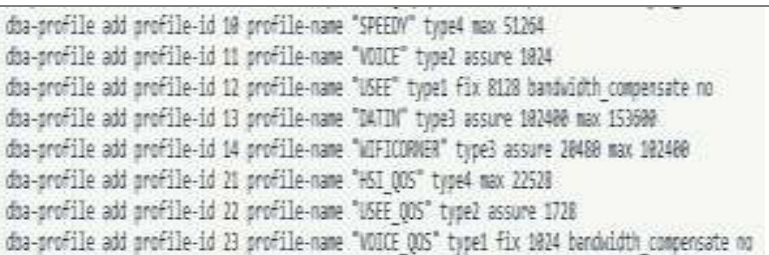 & $\begin{array}{l}\text { Penambahan Profile id dengan penamaan } \\
\text { layanan yang dikeluarkan. }\end{array}$ \\
\hline 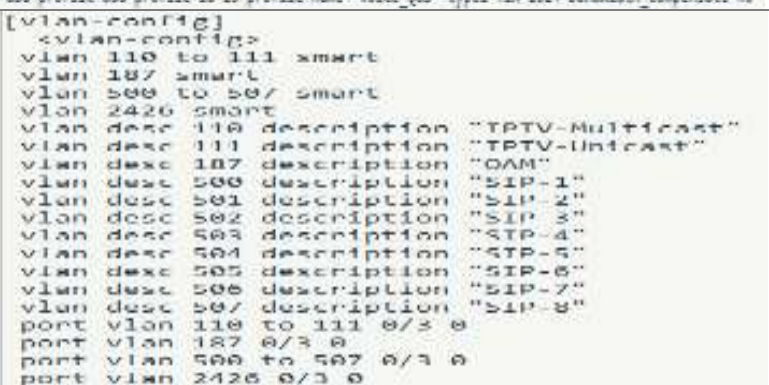 & $\begin{array}{l}\text { Proses penambahan vlan untuk } \\
\text { menggolongkan layanan yang akan diberikan } \\
\text { vlan } 110 \text { vlan IP TV, vlan } 2426 \text { merupakan vlan } \\
\text { internet dan vlan } 505-507 \text { merupakan vlan IP } \\
\text { Voice }\end{array}$ \\
\hline
\end{tabular}




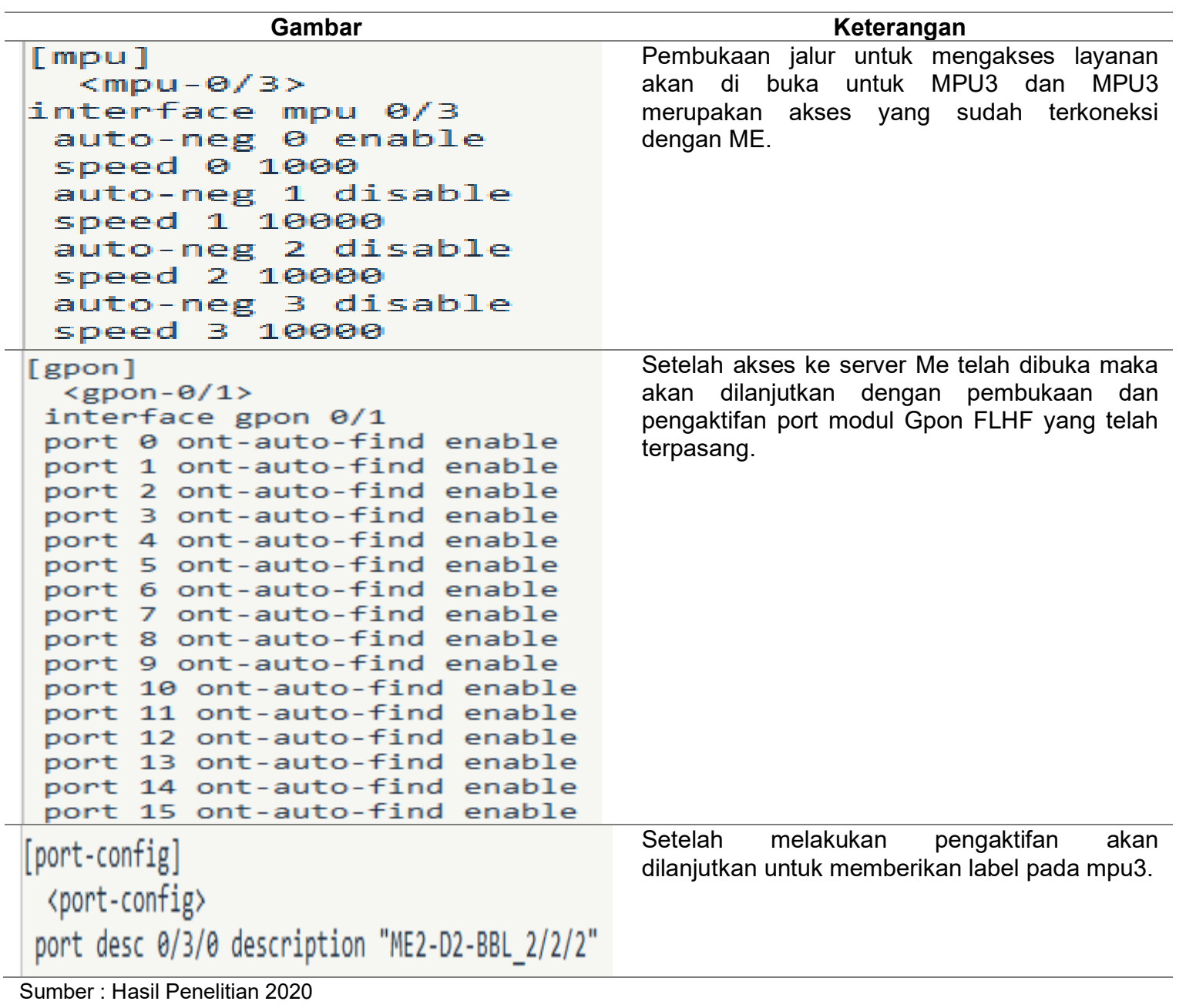

\section{Optimaze}

Proses testing layanan dilakukan dengan mengunakan modem Huawei yang telah disediakan oleh PT Telekomunikasi Indonesia akan dilakukan penambahan layanan Internet terlebih dahulu untuk mengecek kestabilan Jaringan yang sudah dibangun dijelaskan pada tabel berikut:

Tabel 7. Proses Testing Layanan

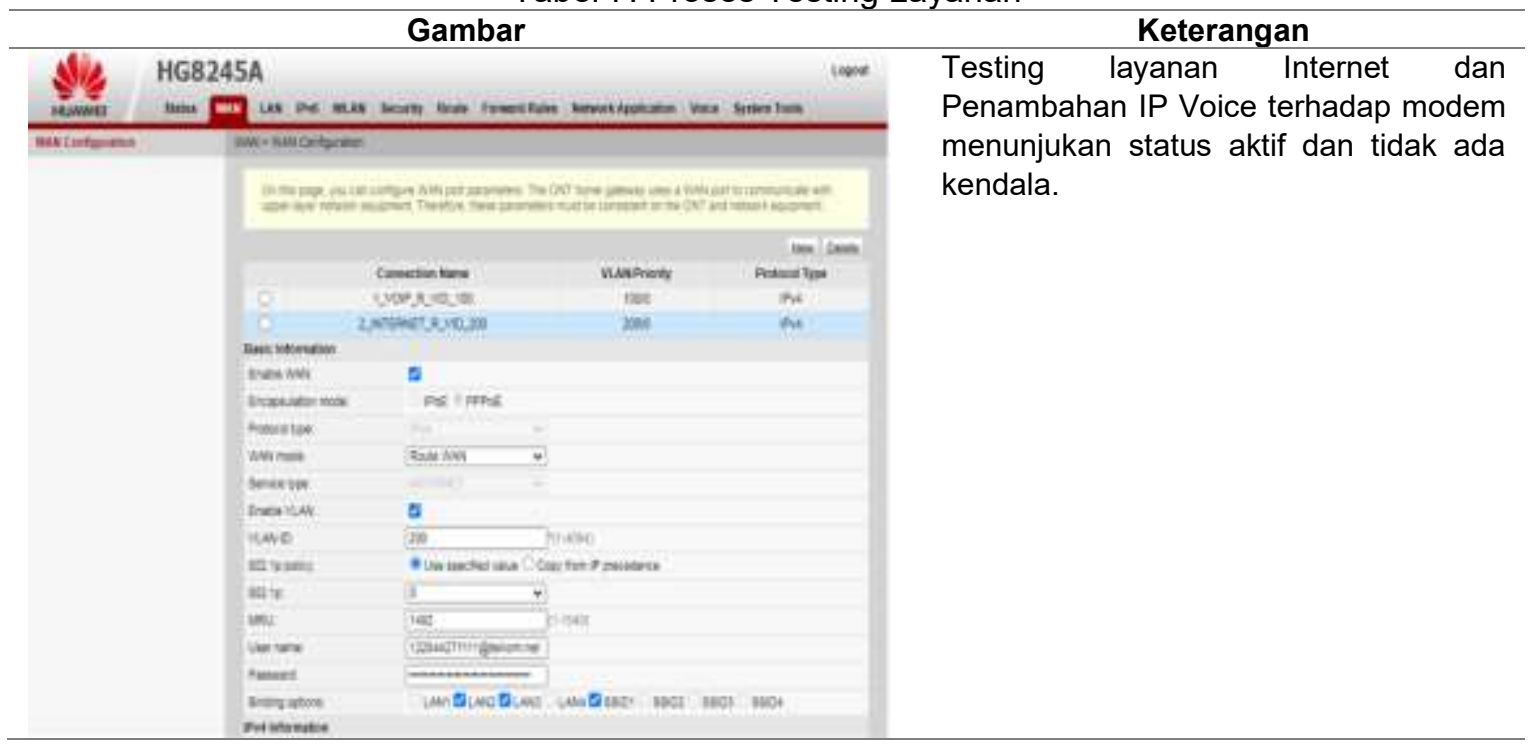


Vol. 5, No. 2, Juni 2021, 63 - 74

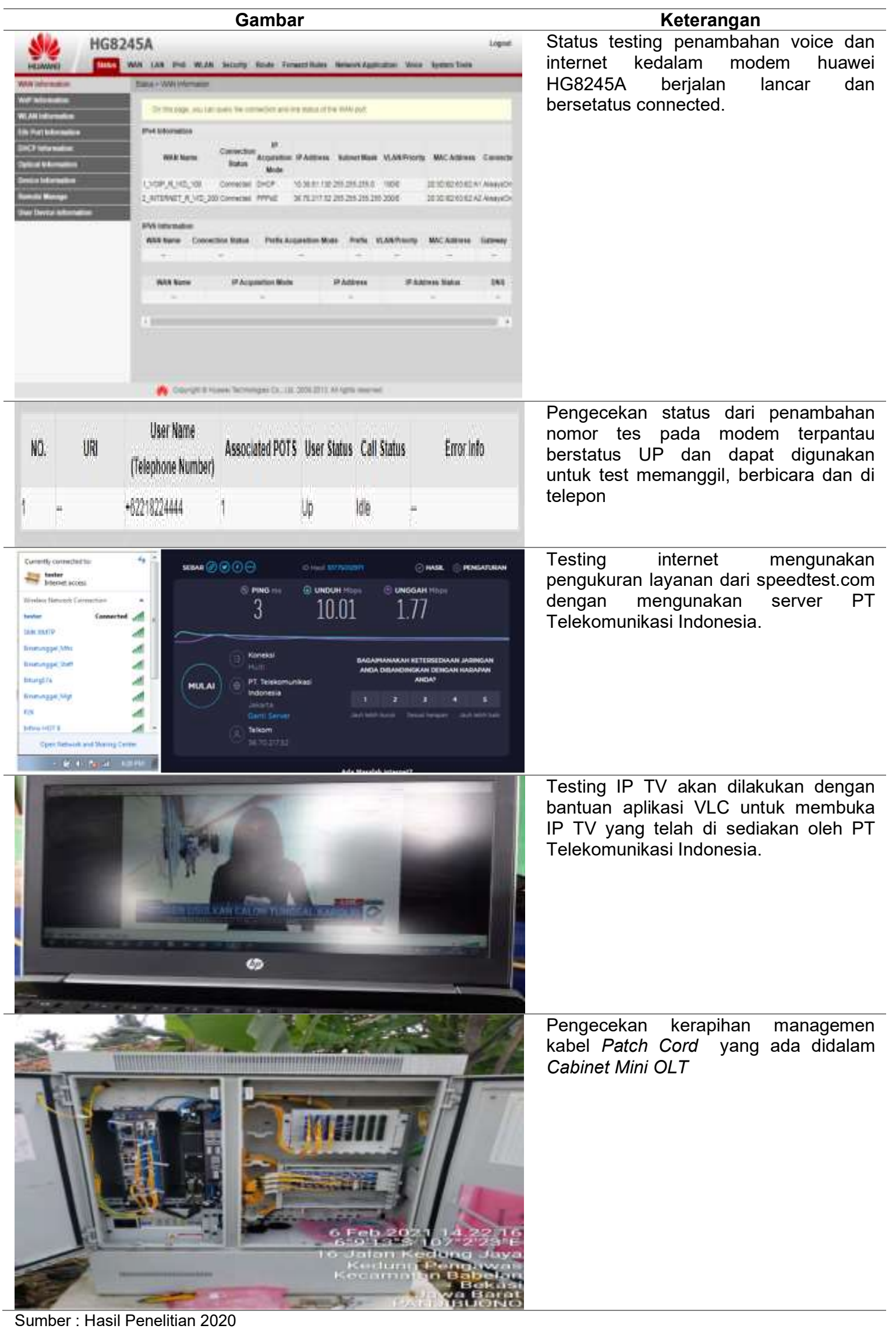

Sumber : Hasil Penelitian 2020 


\section{Kesimpulan}

Berdasarkan hasil penelitian dan pengujian Implementasi Pembangunan Jaringan Mini Optical Line Termination di kawasan Babelan Milik PT Telekomunikasi Indonesia Untuk menjawab masalah yang timbul dapat disimpulkan beberapa poin pencapaian yang didapat berdasarkan tujuan awal yaitu sebagai berikut, dengan pembangunan Mini OLT ini dapat membantu memaksimalkan pembangunan yang dilakukan oleh PT Telekomunikasi Indonesia, dan teknologi yang telah di kembangkan oleh Huawei merupakan solusi yang cukup tepat untuk memperluas jaringan agar dapat mengapai daerah yang belum memiliki akses jaringan.

Saran yang dapat saya berikan setelah mengikuti projek pembangunan jaringan Mini Optical Line Termination ini adalah, dalam obvservasi yang saya lakukan terhadap kegiatan teknis dalam pembangunan dan testing sudah baik, tetapi kegiatan perawatan selanjutnya, diharapkan lebih semangat dan bertanggung jawab dalam setiap melakukan pekerjaan agar apa yang di cita-citakan perusahaan dapat tercapai. Untuk sistem yang sudah berjalang sekarang sudah sangat baik, namun harus lebih ditingkatkan dalam beberapa aspek dan kordinasi antar bagian harus lebih di tingkatkan agar pekerjaan dapat berjalan dengan lancar.

\section{Referensi}

[1] Ananda A, Elektro D, Teknik F, Hasanuddin U. 2019. Pengaruh Kualitas Jaringan Indihome Terhadap Customer Experience Di Pt . PT. Telkom Akses. 67-72.

[2] Asriani F, Susilawati H, Purnomo WH, Pamudji G, Teknik J, Universitas E, Soedirman J, Teknik J, Universitas S, Soedirman J. 2017. Analisis penggunaan fiber optik sebagai sensor kelembaban yang tertanam di dalam beton. Anal. Pengguna. FIBER Opt. SEBAGAI Sens. KELEMBABAN YANG TERTANAM DI DALAM Bet.: 1737-1746.

[3] Di M, Darussalam STO. 2016. Analisis Kualitas Jaringan Akses Indihome Untuk Teknologi Gpon Dan Msan Di Sto Darussalam. J. Karya IIm. Tek. Elektro 1: 27-34.

[4] Djiwandono PI. 2015. Meneliti itu Tidak Sulit: Metodologi Penelitian Sosial dan Pendidikan Bahasa.

[5] Efriyanda O, Faiza D, Hadi A, Studi P, Teknik P, Teknik F, Negeri U. 2014. ANALISIS KINERJA SISTEM KOMUNIKASI SERAT OPTIK DENGAN MENGGUNAKAN METODE POWER LINK BUDGET DAN RISE TIME BUDGET PADA PT.TELEKOMUNIKASI ( Studi Kasus Link Batusangkar - Lintau ). Voteknika 2: 80-86.

[6] Fadhallah RA. 2020. Wawancara. Jakarta: UNJ PRESS. 60 p.

[7] Habib F, Tjahjamooniarsih N, W FTP. 2015. Analisa Rugi-Rugi Serat Optik Menggunakan Optical Time Domain Reflectometer Dengan Aplikasi AQ77932 Emulation.

[8] Suryani H. 2015. Metode Riset Kuantitatif: Teori dan Aplikasi pada Penelitian Bidang Manajemen Dan Ekonomi Islam.

[9] Tantoni A. 2019. Perancangan Blueprint Jaringan Intervlan Routing Menggunakan Model Hirarki Desain Jaringan. J. Transform. (Informasi Pengemb. Iptek) 15: 56-65.

[10] Tantoni A, Ashari M, Zaen MTA. 2020. Analisis Dan Implementasi Jaringan Komputer Brembuk.Net Sebagai Rt/Rw.Net Untuk Mendukung E-Commerce Pada Desa Masbagik Utara. MATRIK J. Manajemen, Tek. Inform. dan Rekayasa Komput. 19: 312-320. 